\title{
Reduction of $\mathrm{Pd}^{2+}$ pre-adsorbed on cyanide-modified $\mathrm{Pt}(111)$ electrodes: adlayer metallization vs. metal-on-metal deposition
}

\author{
Jonathan A. Mwanda and Angel Cuesta*
}

Department of Chemistry, School of Natural and computing Sciences, University of Aberdeen, Aberdeen AB24 3UE, Scotland, UK

*Corresponding Author. E-mail: angel.cuestaciscar@abdn.ac.uk

\section{Abstract:.}

We have studied the reduction of $\mathrm{Pd}^{2+}$ irreversibly and non-covalently immobilized on a cyanide modified Pt (111) electrode using cyclic voltammetry (CV) and in-situ scanning tunnelling microscopy (STM). Contrary to $\mathrm{Cu}^{2+}$, the reduction of which results in the metallisation of the cyanide adlayer (J. Solid State Electrochem. 20 (2015) 1087-1094), reduction of $\mathrm{Pd}^{2+}$ results on the deposition on the $\mathrm{Pt}(111)$ substrate of $\mathrm{Pd}$ triangular nanoislands containing approximately 30 atoms in average and evenly distributed over the electrode surface. A potential excursion below $0.20 \mathrm{~V}$ vs. RHE results in the islands swelling and increasing their surface. This swelling effect is size-dependent, and while the smaller islands increase their area by as much as $60-75 \%$ within the hydrogen region, bigger islands swell by just $12 \%$. We attribute this effect to hydrogen absorption within the palladium islands, which also increases the mobility of the Pd atoms and leads to the formation of larger islands. Cyclic voltammetry suggests that repeated cycling into the hydrogen evolution region results in an increase in the size of epitaxial Pd bidimensional is;lands on $\mathrm{Pt}(111)$, which is consistent with the evolution observed using STM.

Keywords: cyanide-modified Pt(111); electrodeposition; Pd; in-situ STM; cyclic voltammetry 


\section{Introduction}

Metallising with one-atom thick islands a one-molecule thick adlayer chemisorbed on a metal electrode is an attractive method of establishing robust contacts across a group of molecules in a metal-self-assembled monolayer (SAM) - metal sandwich configuration. The main obstacle to achieving this goal is the possibility of the metal being deposited creeping under the SAM and directly depositing on the substrate. Initial attempts of metal deposition on top of a SAM, either from the gas phase [1,2] or electrochemically [3-10], failed, and ultimately led to deposition beneath the SAM and directly onto the substrate. Electrochemical metallisation of an organic SAM was demonstrated by Baunach et al. in 2004 [11]. The procedure involves the pre-adsorption on the SAM-modified electrode of the metal cation $\left(\mathrm{M}^{\mathrm{z+}}\right)$ by simple immersion in a solution containing $\mathrm{M}^{\mathrm{z+}}$, followed by rinsing and subsequent electroreduction in an $\mathrm{M}^{\mathrm{z}}$-free electrolyte. It must be noted, however, that attempts by other groups to metallize SAMs using the same procedure yielded three-dimensional nanoparticles on top of the SAM $[12,13]$, rather than the bi-dimensional islands observed by Kolb and co-workers $[11,14-18]$.

An exciting extension of Kolb's method is to design a strategy that results in the deposition of an ordered array of nanoislands of the same size all over the SAM. In this configuration, all the islands would sandwich the same number of molecules (i.e., electronic transport would be similar across all the junctions), and other interesting properties might result from plasmon excitation or from collective phenomena. Developing this kind of surfaces would require a careful design of the SAM, in order to force the metal to deposit on specific sites. As a first step towards realising this goal, we have attempted the metallisation of cyanide-modified Pt(111) electrodes.

Cyanide adsorbs spontaneously and irreversibly on $\mathrm{Pt}(111)$ through its carbon atom, with the nitrogen atom facing the solution [19-22], forming an ordered $(2 \sqrt{3} \times 2 \sqrt{3}) R 30^{\circ}$ structure [22-24] which might provide a template for the directed metallisation of cyanide with an ordered array of islands. We have recently shown that a variety of metal cations (e.g., $\mathrm{Li}^{+}, \mathrm{Na}^{+}, \mathrm{K}^{+}, \mathrm{Cs}^{+}$and $\mathrm{Cu}^{2+}$ ) interact through noncovalent interactions with the nitrogen atom of adsorbed cyanide [25-27]. In the case of $\mathrm{Cu}^{2+}$, the interaction is strong enough to be irreversible, and $\mathrm{Cu}^{2+}$ remains adsorbed even in the absence of $\mathrm{Cu}^{2+}$ in the solution [28]. Reduction of pre-adsorbed $\mathrm{Cu}^{2+}$ in a $\mathrm{Cu}^{2+}$-free electrolyte, as in Kolb's method, resulted in the reversible metallisation of the cyanide adlayer with mobile bi-dimensional islands, which grow slowly via an Ostwald ripening mechanism [28]. Unfortunately, the mobility of the islands and the resulting Ostwald ripening process prevented achieving the goal of fabricating an ordered array of $\mathrm{Cu}$ islands on top of the cyanide adlayer.

Herein, we report a combined cyclic voltammetry (CV) and in-situ scanning tunnelling microscopy (STM) study of the reduction of $\mathrm{Pd}^{2+}$ immobilized on a cyanide-modified Pt (111) electrode in $\mathrm{Pd}^{2+}$-free perchloric and sulphuric acid solutions, using Kolb's two-step method. Our results provide additional support to our previous claim of a successful metallisation of cyanide with $\mathrm{Cu}$ [28], and highlight the role of the interaction of the adlayer with the metal being deposited in determining the success of the process.

\section{Experimental}

The working electrodes used for CV were bead-type platinum single crystals ( $2 \mathrm{~mm}$ in diameter) prepared according to the method developed by Clavilier et al. [29], oriented and polished parallel to the (111) plane (miscut $<0.05^{\circ}$ ). The Pt(111) electrode used for the STM experiments was a single- 
crystal disc (10 mm in diameter) purchased from MaTeck (Jülich, Germany). Before each experiment, the electrodes were annealed in the flame of a Bunsen burner and cooled in a $\mathrm{H}_{2}-\mathrm{N}_{2}$ atmosphere.

Cyanide-modified Pt(111) electrodes were prepared by immersion of a clean and well-ordered Pt(111) surface in a $0.1 \mathrm{M} \mathrm{KCN}$ (Merck, p.a.) solution for approximately $3 \mathrm{~min}$, after which the electrode was rinsed with ultrapure water Milli-Q water ( $18 \mathrm{M} \Omega \mathrm{cm}, 2 \mathrm{ppb}$ TOC). Pre-adsorption of $\mathrm{Pd}^{2+}$ was achieved by first rinsing the cyanide-modified $\mathrm{Pt}(111)$ electrode with ultrapure water and then immersing the electrode in either $0.1 \mathrm{M} \mathrm{H}_{2} \mathrm{SO}_{4}$ (Merk, suprapur) $+1 \mathrm{mM} \mathrm{PdSO}{ }_{4}$ (Merck, 99+) for subsequent experiments in $0.1 \mathrm{M} \mathrm{H}_{2} \mathrm{SO}_{4}$, or in $0.1 \mathrm{M} \mathrm{HClO}_{4}$ (Merk, p.a.) + $1 \mathrm{mM} \mathrm{PdSO}_{4}$ for subsequent experiments in $0.1 \mathrm{M} \mathrm{HClO}_{4}$, for $5 \mathrm{~min}$, followed by rinsing with ultra-pure Milli-Q water. All solutions were prepared with ultrapure Milli-Q water. All CVs were measured after deaerating the solution with $\mathrm{N}_{2}$ (BOC, Research Grade N5.5)

Platinum wires (Alfa Aesar 99.997\%, $0.5 \mathrm{~mm}$ in diameter) were utilized as auxiliary electrodes. A platinum wire was also used as a quasi-reference electrode in the in-situ STM experiments, while in $\mathrm{CV}$ a reversible hydrogen electrode (RHE) was used as reference. All potentials in the text are referred to the RHE.

STM images were recorded using a PicoLE Molecular Imaging with a PicoScan 2100 controller, using tungsten tips etched from a polycrystalline $\mathrm{W}$ wire $(0.25 \mathrm{~mm}$ in diameter) in $2 \mathrm{M} \mathrm{NaOH}$, and subsequently coated with electrophoretic paint to reduce the faradaic current at the tip/electrolyte interface. All images were recorded in the constant-current mode.

\section{Results}

\subsection{Cyclic voltammetry}

Fig. 1 shows the first (solid black line) and second (dotted black line) CVs in a $\mathrm{Pd}^{2+}$-free $0.1 \mathrm{M} \mathrm{HClO}_{4}$ solution of a cyanide-modified $\mathrm{Pt}(111)$ electrode on which $\mathrm{Pd}^{2+}$ had been pre-adsorbed. The electrode was immersed in the electrolyte at $0.80 \mathrm{~V}$, and the potential was then scanned in the negative direction at $0.05 \mathrm{~V} \mathrm{~s}^{-1}$. The blue line corresponds to the characteristic CV of cyanide-modified Pt (111) (i.e., when no $\mathrm{Pd}^{2+}$ or any other species has been pre-adsorbed). The difference between the black and blue lines in Fig. 1 is clear evidence that $\mathrm{Pd}^{2+}$ adsorbs irreversibly on cyanide-modified $\mathrm{Pt}(111)$. Most likely, the $\mathrm{Pd}^{2+}$ ions attached to the cyanide layer retain part of their solvation layer.

The first negative potential sweep (solid black line in Fig. 1) is characterised by a broad cathodic feature extending from 0.80 to ca. $0.50 \mathrm{~V}$, followed by a cathodic peak at $0.42 \mathrm{~V}$, the counterpart of which appears at $0.50 \mathrm{~V}$ in the reverse positive sweep. The second negative sweep (dotted line in Fig. 1) is characterized by the absence of the broad cathodic wave between 0.80 and $0.50 \mathrm{~V}$ and a decrease of the intensity of the peak at $0.42 \mathrm{~V}$. The second positive sweep overwrites the first one, suggesting that the second negative sweep has not provoked any additional changes on the electrode surface. The difference between the charge in the first and second negative sweeps (integrated between 0.80 and $0.20 \mathrm{~V}$ ) amounts to $61 \mu \mathrm{C} \mathrm{cm}^{-2}$, which corresponds to the deposition of $0.13 \mathrm{ML}$ of Pd. As long as the negative potential limit is kept above $0.20 \mathrm{~V}$, no more changes can be observed in the CV after the second sweep, and the CVs are identical in $0.1 \mathrm{M} \mathrm{H}_{2} \mathrm{SO}_{4}$ and $0.1 \mathrm{M} \mathrm{HClO}_{4}$.

The CV of a cyanide-modified Pt (111) electrode in the absence of pre-adsorbed $\mathrm{Pd}^{2+}$ (blue line in Fig. 1) also shows a less pronounced cathodic peak just below $0.50 \mathrm{~V}$. We have previously shown that the broad process observed in the CV of cyanide-modified $\mathrm{Pt}(111)$ between $0.05 \mathrm{~V}$ and $0.45 \mathrm{~V}$, including the above-mentioned peak, corresponds to the concerted transfer of a proton and an electron to $\mathrm{CN}_{\mathrm{ad}}$ to form $(\mathrm{CN})_{x} \mathrm{H}_{\text {ad }}$ [27]. We have also shown that the interaction of the cyanide adlayer with $\mathrm{M}^{2+}$ ions, either in equilibrium with the cation in the solution [26,30], or after irreversible adsorption of $\mathrm{M}^{2+}[28]$, 
affects the shape of this hydrogen adsorption region, due to the competition between $\mathrm{M}^{2+}$ and $\mathrm{H}^{+}$for the same adsorption sites $[26,28,31]$. However, in all those cases the hydrogen adsorption process remains highly reversible, while the process with cathodic and anodic peaks at 0.42 and $0.50 \mathrm{~V}$, respectively, that emerges after reduction of the pre-adsorbed $\mathrm{Pd}^{2+}$ (Fig. 1) shows some degree of irreversibility. Sulphate ad-/desorption on Pd is observed at ca. $0.20 \mathrm{~V}$, overlapping with hydrogen adsorption, and Pd dissolution and redeposition can be discarded. We attribute, therefore, these peaks to the ad-/desorption of $\mathrm{OH}$ on, or possibly to the oxidation/reduction of, the palladium islands deposited in the first cycle.

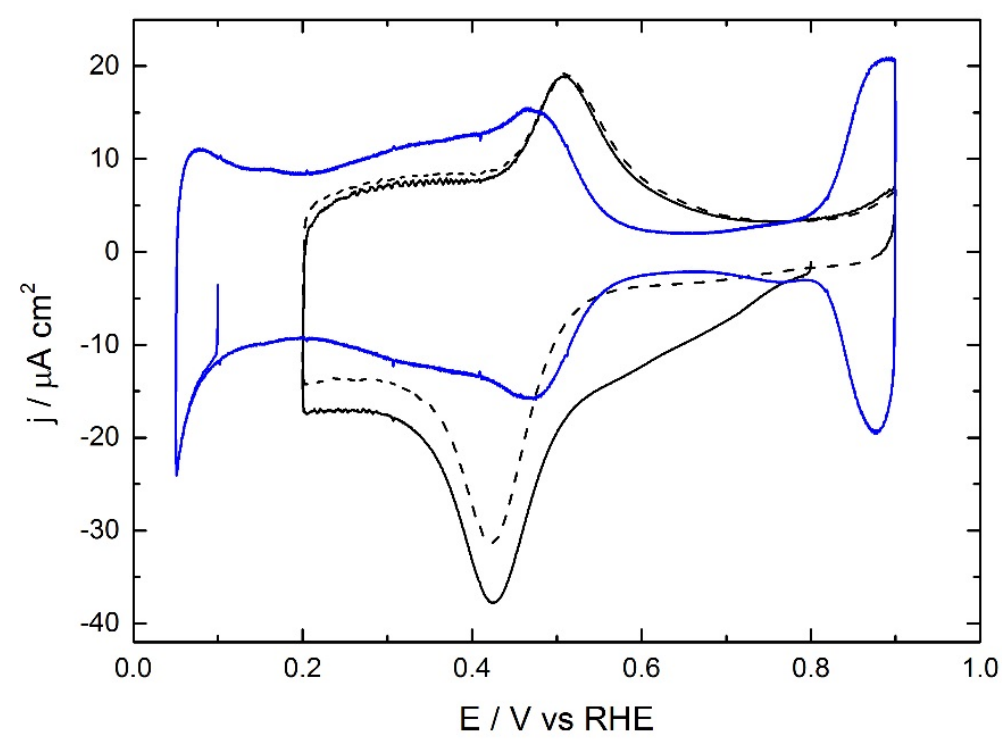

Figure 1. First (solid black line) and second (dotted black line) cyclic voltamograms in $\mathrm{Pd}^{2+}$ free $0.1 \mathrm{M} \mathrm{HClO}_{4}$ at $0.05 \mathrm{Vs}^{-1}$ of a cyanide-modified $\mathrm{Pt}(111)$ electrode on which $\mathrm{Pd}^{2+}$ had been pre-adsorbed. The blue line corresponds to the cyclic voltammogram of cyanide-modified Pt (111) without pre-adsorbed $\mathrm{Pd}^{2+}$.

Increasing the negative potential limit beyond $0.20 \mathrm{~V}$ results in clear changes in the voltammetric profile, which slowly evolves with cycling until a steady-state $\mathrm{CV}$ is reached (Fig. 2). The most significant changes in $0.1 \mathrm{M} \mathrm{H}_{2} \mathrm{SO}_{4}$ are the slow emergence of a very reversible process at ca. $0.21 \mathrm{~V}$, and the decrease in intensity, accompanied by a slight shift to more positive potentials, of the cathodic process originally appearing around $0.42 \mathrm{~V}$. The anodic counterpart of this peak at ca. $0.50 \mathrm{~V}$ also decreases in intensity and becomes broader. In $0.1 \mathrm{M} \mathrm{HClO}_{4}$ the peaks corresponding to the very reversible process at $0.21 \mathrm{~V}$ are much less sharp than in sulphuric acid, which is a clear evidence that (bi)sulphate adsorption/desorption must be associated to the process in the latter case. Similar peaks have been observed in the CVs of epitaxial deposits of palladium on $\mathrm{Pt}(111)$ in sulphuric acid solutions, and have been attributed to the ad-/desorption of hydrogen and concomitant de-/adsorption of (bi)sulphate [31-33]. Perchlorate ions adsorb much more weakly than sulphate, and in perchloric acid hydrogen adsorption is not accompanied by the concomitant specific adsorption of the anion. Apart from this difference, the steady-state voltammograms are nearly identical in perchloric acid and sulphuric acid. The fact that potentials more negative than $0.20 \mathrm{~V}$ are necessary to provoke these changes in the voltammetric profile is a clear indication that the changes are generated by hydrogen adsorption on (and absorption in) Pd. Overall, the results in Fig. 2 suggest the epitaxial deposition of bidimensional Pd islands on Pt(111). 
The charge density involved in the reversible process at $0.21 \mathrm{~V}$ is directly related to the Pd coverage on $\mathrm{Pt}(111)[34,35]$, which can be calculated as:

$$
\theta_{P d}=\frac{q_{P d}}{q_{P d}^{\max }}
$$

Where $q_{\mathrm{Pd}}$ is the actual charge under peak at $0.21 \mathrm{~V}$ and $q_{\mathrm{Pd}}{ }^{\max }$ is the charge under the peak for a full palladium monolayer, reported as $320 \mu \mathrm{C} \mathrm{cm}^{-2}$ [34]. The charge under the peak when the steady-state voltammogram is reached is of ca. $35 \mu \mathrm{C} \mathrm{cm}{ }^{-2}$, which corresponds to $0.11 \mathrm{ML}$. This is in excellent agreement with the $0.13 \mathrm{ML}$ of $\mathrm{Pd}$ estimated above from the reduction of the pre-adsorbed $\mathrm{Pd}^{2+}$ initially present on the surface.
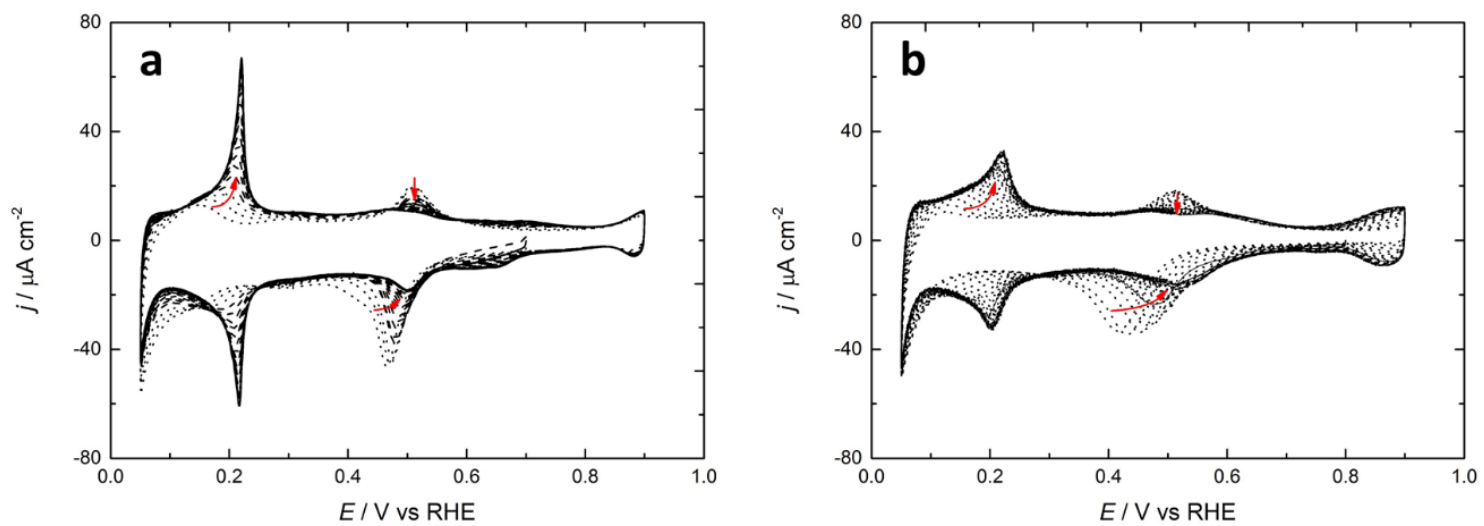

Figure 2. Evolution with cycling of the voltammogram at $0.05 \mathrm{~V} \mathrm{~s}^{-1}$ of a cyanide-modified $\mathrm{Pt}(111)$ electrode on which preadsorbed $\mathrm{Pd}^{2+}$ had been reduced during a previous potential sweep between 0.80 and $0.20 \mathrm{~V}$ in a) $0.1 \mathrm{M} \mathrm{H}_{2} \mathrm{SO}_{4}$ b) $0.1 \mathrm{M}$ $\mathrm{HClO}_{4}$. The arrows indicate the evolution of the peaks. The solid line corresponds to the final, stationary state, while the dotted lines illustrate the gradual changes during cycling.

\subsection{In-situ STM}

In-situ STM was used to study the nanoscale morphological changes associated with the voltammetric features described in the previous section. At $0.80 \mathrm{~V}$, and before any excursion to more negative potentials, the typical honeycomb structure recently reported by us $[25,26,28]$ is typically observed (not shown), suggesting the presence of a $(2 \sqrt{3} \times 2 \sqrt{3}) R 30^{\circ}$ cyanide adlayer, on which $\mathrm{Pd}^{2+}$ has been immobilised through coordination to the nitrogen atom of adsorbed cyanide.

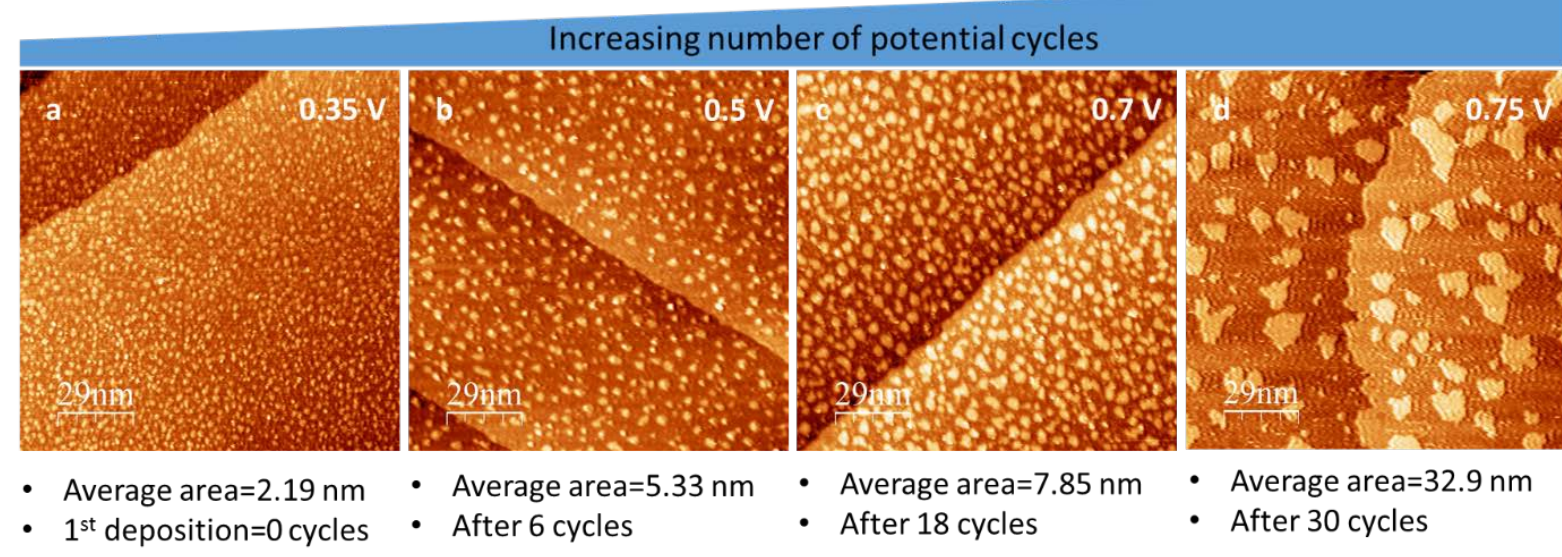

Figure 3. In situ STM images after reduction of pre-adsorbed $\mathrm{Pd}^{2+}$ on cyanide-modified $\mathrm{Pt}(111)$ in $\mathrm{Pd}^{2+}-$ free $0.1 \mathrm{M} \mathrm{H}_{2} \mathrm{SO}_{4}$. a) At $E=0.35 \mathrm{~V}$ after initial deposition with no subsequent cycling, $U_{\mathrm{T}}=0.20 \mathrm{~V}$ (tip negative; b) At $E=0.5 \mathrm{~V}$ after 6 cycles 
between 0.05 and $0.90 \mathrm{~V}, U_{\mathrm{T}}=0.20 \mathrm{~V}$ (tip negative); c) At $E=0.7 \mathrm{~V}$ after 18 cycles between 0.05 and $0.90 \mathrm{~V}, U_{\mathrm{T}}=0.50 \mathrm{~V}$ (tip negative); d) At $E=0.75 \mathrm{~V}$ after 30 cycles between 0.05 and $0.90 \mathrm{~V}, U_{\mathrm{T}}=0.50 \mathrm{~V}$ (tip negative). All images $145 \times 145 \mathrm{~nm}^{2}$ in size, $I_{\mathrm{T}}=2 \mathrm{nA}$.

Fig. 3 illustrates the changes in the surface morphology after reducing the $\mathrm{Pd}^{2+}$ pre-adsorbed on a cyanide-modified Pt(111) electrode in $0.1 \mathrm{M} \mathrm{H}_{2} \mathrm{SO}_{4}$ (Fig. 3a), and subsequently submitting the surface to successive potential cycles between 0.05 and $0.90 \mathrm{~V}$ until a steady-state $\mathrm{CV}$ is reached (Figs. $3 \mathrm{~b}$ to d). As shown in Fig. 3a, just negative of the reduction peak at $0.42 \mathrm{~V}$ in the first $\mathrm{CV}$, small triangular islands with an average surface area of ca. $2.2 \mathrm{~nm}^{2}$ (i.e., containing in average $37 \mathrm{Pd}$ atoms) appear spread all over the surface (see the Supporting Information for the calculation of the average area of the islands). The islands have an apparent height of ca. $3 \AA$ A high, i.e., they are just one Pd atom thick. No preferential nucleation of islands at step sites or elsewhere can be observed. Once formed, no significant changes to the size, shape or distribution of the islands are observed within the potential window between 0.20 and $0.90 \mathrm{~V}$, in good agreement with the results reported in the previous section that the $\mathrm{CV}$ does not change at all upon continuous cycling within these potential limits. This behaviour is different to that recently reported for the nanoislands resulting from reduction of $\mathrm{Cu}^{2+}$ pre-adsorbed on cyanide-modified $\mathrm{Pt}(111)$ [28], which were found to be rather mobile and increase their size by Ostwald ripening. No differences are observed when the same experiment is carried out in $0.1 \mathrm{M}$ $\mathrm{HClO}_{4}$

The morphological changes induced by successive cycling down to $0.05 \mathrm{~V}$ are illustrated in Figs. $3 \mathrm{~b}$-d. The size of the palladium islands clearly increases in size with increasing number of cycles. We attribute this gradual evolution to an increase in the mobility of Pd adatoms due to hydrogen adsorption on and absorption in the islands, which favours smaller islands merging into larger ones (Ostwald ripening). The final state, corresponding to the situation in which no further change in the voltammetric profile results from additional cycling, is shown in Fig. $3 \mathrm{~d}$. This state is characterized by large islands with an average surface area above $30 \mathrm{~nm}^{2}$, i.e., containing more than $500 \mathrm{Pd}$ atoms. The shape of the islands in Figs. 3a-d strongly suggest that they have grown epitaxially on the Pt(111) substrate. The islands in Figs. 3a-d occupy approximately $16-17 \%$ of the surface (Fig. S1), in reasonable agreement with the deposition of 0.13 and $0.11 \mathrm{ML}$ of Pd deduced from integration of the CV in Fig. 1 and from integration of the hydrogen adsorption peaks in Fig. 2, respectively.

Figure 4 illustrates the effect on individual islands of decreasing the potential below $0.20 \mathrm{~V}$, into the hydrogen adsorption and evolution regions. The lower part of the image in Figure 4a was recorded at $0.70 \mathrm{~V}$, and the potential was stepped to $0.10 \mathrm{~V}$ at approximately half image. This potential step results in an immediate expansion in the size of the islands, while the number of islands remains unchanged. The effect is better observed in the inset to Fig. 4a, which is a zoom on a single island the area of which expands by ca. $60 \%$ at $0.10 \mathrm{~V}$ (Fig. S2). As far as we know, this swelling of the bidimensional Pd islands, which seems to be associated with the onset of hydrogen evolution, has never been observed before. Interestingly, the magnitude of the expansion is size-dependent: small islands increase their area by as much as 60 to $75 \%$ when the potential is stepped into the hydrogen region, while the bigger islands expand by barely $12 \%$ (Fig. S3).

Figs. $4 \mathrm{~b}$ to $\mathrm{d}$ show images at $0.25 \mathrm{~V}, 0.15 \mathrm{~V}$ and $0.05 \mathrm{~V}$, respectively, of the same area once the final, steady state $\mathrm{CV}$ has been reached. The images show several interesting features associated with decreasing the potential below $0.20 \mathrm{~V}$ : (i) smaller islands (see area highlighted within a blue ellipse) merge into larger islands,; (ii) the island edges become fizzy (see Figs. $4 c$ and d, and the corresponding insets), a usual indication of high mobility; and (iii) higher contrast features appear within the islands (see Figs. 4c and, especially, $d$, and the corresponding insets). Again, exactly the same results were obtained when the same experiment was performed in $0.1 \mathrm{M} \mathrm{HClO}_{4}$. 


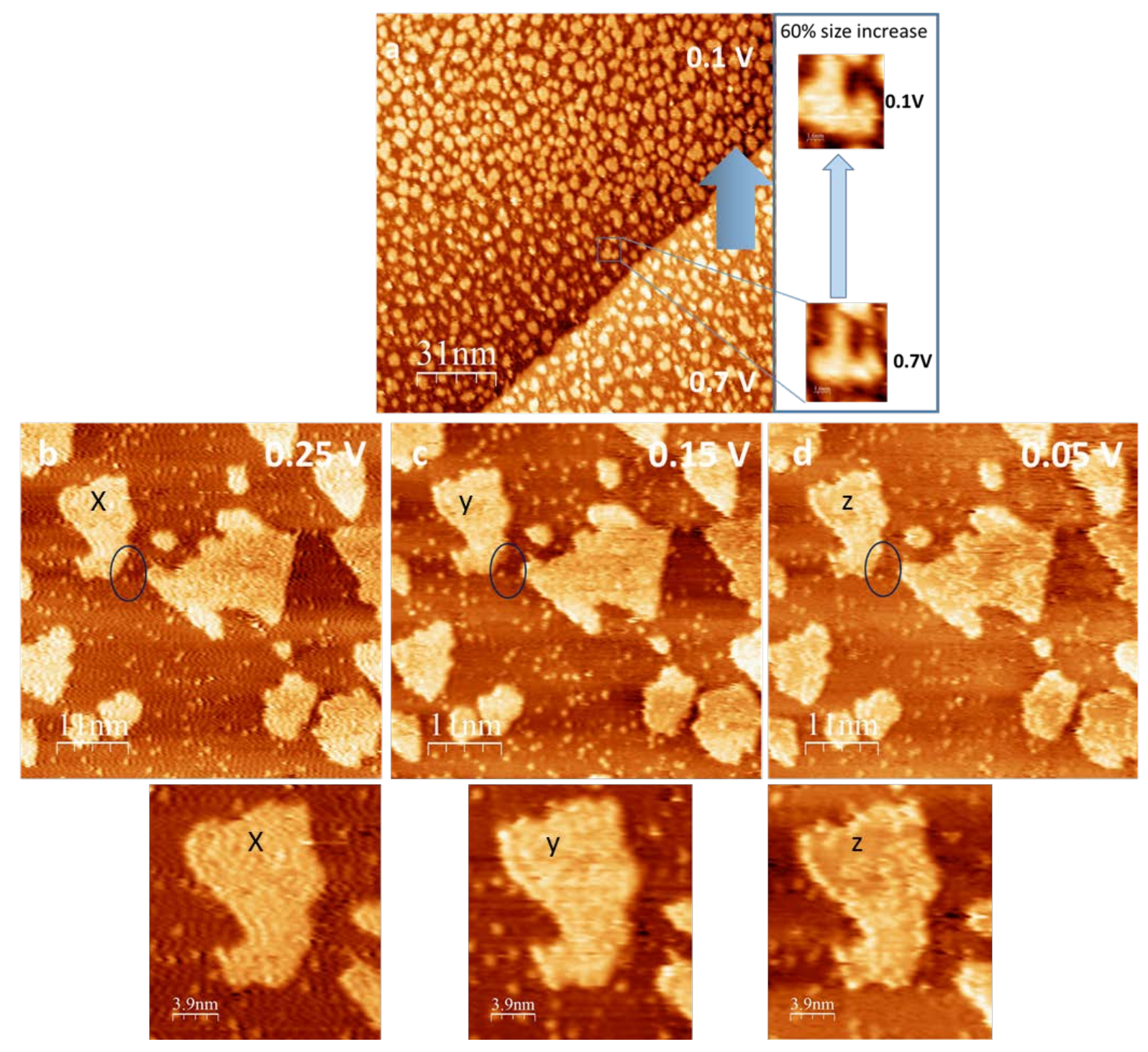

Figure 4. In situ STM images after deposition of pre-adsorbed $\mathrm{Pd}^{2+}$ on cyanide-modified $\mathrm{Pt}(111)$ in $\mathrm{Pd}^{2+}$-free $0.1 \mathrm{M} \mathrm{H}_{2} \mathrm{SO}_{4}$. a) $152 \times 152 \mathrm{~nm}^{2}$, electrode potential stepped halfway through the image from $E=0.7 \mathrm{~V}\left(U_{\mathrm{T}}=0.50 \mathrm{~V}\right.$, tip negative) to $E=0.1 \mathrm{~V}$ $\left(U_{T}=0.10 \mathrm{~V}\right.$, tip positive). The inset is a zoom $\left(7.9 \times 9 \mathrm{~nm}^{2}\right)$ into a single island. The middle row shows STM images $(55 \times 55$ $\left.\mathrm{nm}^{2}\right)$ of the same area of the electrode at $E=0.25 \mathrm{~V}\left(U_{\mathrm{T}}=0.10 \mathrm{~V}\right.$, tip negative) (b), $E=0.15 \mathrm{~V}\left(U_{\mathrm{T}}=0.10 \mathrm{~V}\right.$, tip postive) (c), and $E=0.05 \mathrm{~V}\left(U_{T}=0.10 \mathrm{~V}\right.$, tip postive) (d). The bottom row is a zoom $\left(19.3 \times 21 \mathrm{~nm}^{2}\right)$ into a single island showing the effect on its topography of decreasing the electrode potential into the hydrogen adsorption and evolution regions. All images acquired at tunneling current $l_{\mathrm{T}}=2 \mathrm{nA}$.

\section{Discussion}

The observation of a negative current at potentials more negative than $0.80 \mathrm{~V}$ in the $\mathrm{CV}$ in a $\mathrm{Pd}^{2+}$-free solution of a cyanide-modified $\mathrm{Pt}(111)$ electrode on which $\mathrm{Pd}^{2+}$ had been pre-adsorbed (Fig. 1), and the observation using STM of small, one atom thick, islands forming on the electrode surface under these conditions, are solid evidence that that negative current corresponds to the reduction of the pre-adsorbed $\mathrm{Pd}^{2+}$ to $\mathrm{Pd}$, resulting in the formation of small, bidimensional islands of metallic palladium. The critical question is whether these bidimensional $\mathrm{Pd}$ nanoislands have been deposited on the cyanide adlayer (sandwiching it between the island and the Pt (111) substrate), as we have recently proposed for the reduction of pre-adsorbed $\mathrm{Cu}^{2+}$ on cyanide-modified Pt (111) [28], or directly onto the Pt surface.

Contrary to similar experiments with pre-adsorbed $\mathrm{Cu}^{2+}[28]$, the $\mathrm{Pd}$ atoms in the islands formed upon reduction of $\mathrm{Pd}^{2+}$ ions pre-adsorbed on the cyanide-modified $\mathrm{Pt}(111)$ surface cannot be re-oxidised to 
the ionic $\mathrm{Pd}^{2+}$ state, as they do not disappear even at potentials as positive as $1.00 \mathrm{~V}$. This is confirmed by the fact that the honeycomb structure typically observed when $\mathrm{M}^{\mathrm{z+}}$ cations are coordinated to the nitrogen end of the cyanide adlayer [26-28] does not reappear once the preadsorbed $\mathrm{Pd}^{2+}$ ions have been reduced. This, however, is not necessarily an evidence that Pd has deposited directly on the metal surface, and not on the cyanide adlayer, as irreversible metallisation of mercaptopyridine SAMs with Pd has been reported by Baunach et al. [11] and Silien et al. [13]. However, while the copper islands formed by reduction of pre-adsorbed $\mathrm{Cu}^{2+}$ are rather mobile, and appear to grow with time via Ostwald ripening [28], in this case the Pd islands are very static, and no change in the shape or size of the islands can be observed, as long as the potential is not made more negative than $0.20 \mathrm{~V}$. Furthermore, instead of the rather undefined shape of the $\mathrm{Cu}$ islands metalizing the cyanide adalyer [28], in the present case the Pd islands have a clear triangular shape. All these facts suggest that reduction of $\mathrm{Pd}^{2+}$ pre-adsorbed on cyanide-modified $\mathrm{Pt}(111)$ results in the epitaxial deposition of $\mathrm{Pd}$ on Pt. At the same time, they provide additional support to our previous claim that reduction of $\mathrm{Cu}^{2+}$ pre-adsorbed on cyanide-modified $\mathrm{Pt}(111)$ results in the metallization of the cyanide adlayer with bidimensional $\mathrm{Cu}$ islands [28]. This sensitivity to the metal being reduced, which has not been observed in previous works with other SAMs, suggests that the interaction between the metal being deposited and the molecules in the SAM plays an important role in determining the success of themetallisation process. The charge under the broad cathodic wave commencing at $0.85 \mathrm{~V}$ in Fig. 1 is of $61 \mu \mathrm{C} \mathrm{cm}^{-2}$, which would correspond to a final coverage of $\mathrm{Pd}$ on Pt(111) of ca. 13\%. This is similar to the surface coverage by bidimensional islands (ca. 16-17\%) obtained from analysing the corresponding STM images, which is in excellent agreement with the coverage expected (16.7\%) if all the tunnelling maxima in the STM images of the honeycomb structure observed before reduction of the pre-adsorbed $\mathrm{Pd}^{2+}$ are attributed to metal cations interacting non-covalently with $\mathrm{CN}_{\mathrm{ad}}$, as we have proposed in previous work [26-28].

Once the pre-adsorbed $\mathrm{Pd}^{2+}$ has been reduced to $\mathrm{Pd}$, extending the negative potential limit into the hydrogen evolution region results in gradual but dramatic changes in the $\mathrm{CV}$. Comparison of the final $\mathrm{CV}$ with those of $\mathrm{Pd}$ monolayers on $\mathrm{Pt}(111)$ [34,35] strongly suggest that the changes are due to the gradual coalescence of the initial islands into larger ones, as confirmed by STM imaging (see Fig. 3). The increase of the size of the islands will change the energetics of hydrogen adsorption, which will be initially dominated by edge sites, $\mathrm{Pd}(111)$ terrace sites becoming more and more numerous as the islands grow. In $0.1 \mathrm{M} \mathrm{H}_{2} \mathrm{SO}_{4}$, the energetics of sulphate adsorption as well as the possibility of forming extended bidimensional domains of the $(2 \sqrt{ } 3 \times 2 \sqrt{ } 3) R 30^{\circ}$ structure will also contribute to the changes in the shape of the $\mathrm{CV}$. The driving force behind the increase of the island size must be the increased mobility of the palladium atoms. This enhanced mobility cannot be due to underpotential deposited hydrogen $\left(\mathrm{H}_{\text {upd }}\right)$, as this occurs at the peaks just positive of $0.20 \mathrm{~V}$ (Fig. 2). It must be, therefore, due to hydrogen absorbed within the Pd islands. The latter assertion is supported by the observation, unprecedented to the best of our knowledge, of an expansion of the area covered by each individual bi-dimensional $\mathrm{Pd}$ island by up to $60 \%$ at potentials more negative than $0.1 \mathrm{~V}$ (Fig. 4). This phenomenon is similar to the well-known deformation of the crystal lattice of bulk Pd upon hydrogen absorption, although in the present case the process is completely reversible. This reversibility is certainly due to the bi-dimensional nature of the islands and to their small size. Interestingly, the swelling effect is smaller in bigger islands, in which hydrogen absorption results in an enhanced contrast at the rims of the islands and in a fraction of the interior of the islands. We ignore whether this enhanced contrast is due to an electronic effect or to an actual topographical accident, although this observation might suggest that the lateral expansion of smaller islands, which accommodates the structural changes associated to hydrogen absorption, is substituted in bigger islands by a vertical displacement of the atoms at the absorption site. 


\section{Conclusion}

We have attempted the metallization of the cyanide adlayer of cyanide-modified Pt (111) electrodes by the reduction of $\mathrm{Pd}^{2+}$ pre-adsorbed on the adlayer in $\mathrm{Pd}^{2+}$ free acidic solutions. However, and contrary to the recently reported case of $\mathrm{Cu}^{2+}[28]$, the process results in the epitaxial deposition of bidimensional Pd islands on the Pt(111) substrate. The clear differences observed, both in the voltammetric profile and in the surface morphology and island mobility, as revealed by STM, between the results reported here and those reported in [28], provide additional support to our previous claim that reduction of $\mathrm{Cu}^{2+}$ pre-adsorbed on cyanide-modified $\mathrm{Pt}(111)$ electrodes results in the metallisation of the cyanide adlayer. This sensitivity to the metal being reduced is in contradiction with previous reports of the electrochemical metallisation of adsorbed monolayers $[11,14,15,18]$, and suggests that the interaction between the metal and the adlayer plays a relevant role in the success of the metallisation process. In the case of $\mathrm{Cu}$, the fact that cyanide is known to stabilise $\mathrm{Cu}^{+}$might play a role in the behaviour observed when reducing $\mathrm{Cu}^{2+}$ pre-adsorbed on cyanide-modified $\mathrm{Pt}(111)$.

Our results also show that hydrogen ad-/absorption considerably increases the mobility of the palladium atoms deposited on $\mathrm{Pt}(111)$, provoking the coalescence of small islands into larger ones. The increased mobility coincides with a swelling effect, by which the islands expand their size by as much as $60-75 \%$ in the hydrogen evolution region. We have attributed the increased surface mobility of $\mathrm{Pd}$ atoms to both adsorption and absorption of hydrogen, and the expansion of the islands to hydrogen absorption within the Pd islands, a process reminiscent of hydrogen absorption in bulk Pd. However, in the case reported here the process is completely reversible, and the swelling effect decreases with the increasing island size, probably due to the increasing amount of energy associated to displacing a larger number of atoms.

\section{Acknowledgement}

The support of the University of Aberdeen is gratefully acknowledged.

\section{References}

[1] D.R. Jung, A.W. Czanderna, Chemical and physical interactions at metal/self-assembled organic monolayer interfaces, Crit. Rev. Solid State Mater. Sci. 19 (1994) 1-54.

[2] E.L. Smith, C.A. Alves, J.W. Anderegg, M.D. Porter, L.M. Siperko, Deposition of metal overlayers at end-group-functionalized thiolate monolayers adsorbed at gold. 1. Surface and interfacial chemical characterization of deposited copper overlayers at carboxylic acidterminated structures, Langmuir. 8 (1992) 2707-2714.

[3] F.P. Zamborini, J.K. Campbell, R.M. Crooks, Spectroscopic, Voltammetric, and Electrochemical Scanning Tunneling Microscopic Study of Underpotentially Deposited Cu Corrosion and Passivation with Self-Assembled Organomercaptan Monolayers, Langmuir. 14 (1998) 640647.

[4] H. Hagenström, M.A. Schneeweiss, D.M. Kolb, Modification of a Au(111) Electrode with Ethanethiol. 2. Copper Electrodeposition, Langmuir. 15 (1999) 7802-7809.

[5] L. Sun, R.M. Crooks, Imaging of Defects Contained within n-Alkylthiol Monolayers by Combination of Underpotential Deposition and Scanning Tunneling Microscopy: Kinetics of Self-Assembly, J. Electrochem. Soc. 138 (1991) L23-L25.

[6] M. Nishizawa, T. Sunagawa, H. Yoneyama, Underpotential Deposition of Copper on Gold Electrodes through Self-Assembled Monolayers of Propanethiol, Langmuir. 13 (1997) 52155217.

[7] S.E. Gilbert, O. Cavalleri, K. Kern, Electrodeposition of Cu Nanoparticles on DecanethiolCovered Au(111) Surfaces: An in Situ STM Investigation, J. Phys. Chem. 100 (1996) 1212312130. 
[8] O. Cavalleri, A.M. Bittner, H. Kind, K. Kern, T. Greber, Copper Electrodeposition on Alkanethiolate Covered Gold Electrodes, Z. Phys. Chem. 208 (1999) 107-136.

[9] D. Oyamatsu, S. Kuwabata, H. Yoneyama, Underpotential deposition behavior of metals onto gold electrodes coated with self-assembled monolayers of alkanethiols, J. Electroanal. Chem. 473 (1999) 59-67.

[10] M.A. Schneeweiss, H. Hagenström, M.J. Esplandiu, D.M. Kolb, Electrolytic metal deposition onto chemically modified electrodes, Appl. Phys. A. 69 (1999) 537-551.

[11] T. Baunach, V. Ivanova, D.M. Kolb, H.G. Boyen, P. Ziemann, M. Büttner, P. Oelhafen, A New Approach to the Electrochemical Metallization of Organic Monolayers: Palladium Deposition onto a 4,4'-Dithiodipyridine Self-Assembled Monolayer, Adv. Mater. 16 (2004) 2024-2028.

[12] O. Shekhah, C. Busse, A. Bashir, F. Turcu, X. Yin, P. Cyganik, A. Birkner, W. Schuhmann, C. Woll, Electrochemically deposited Pd islands on an organic surface: the presence of Coulomb blockade in STM I(V) curves at room temperature, Phys. Chem. Chem. Phys. 8 (2006) 33753378.

[13] C. Silien, D. Lahaye, M. Caffio, R. Schaub, N.R. Champness, M. Buck, Electrodeposition of Palladium onto a Pyridine-Terminated Self-Assembled Monolayer, Langmuir. 27 (2011) 25672574.

[14] V. Ivanova, T. Baunach, D.M. Kolb, Metal deposition onto a thiol-covered gold surface: A new approach, Electrochim. Acta. 50 (2005) 4283-4288.

[15] M. Manolova, V. Ivanova, D.M. Kolb, H.G. Boyen, P. Ziemann, M. Büttner, A. Romanyuk, P. Oelhafen, Metal deposition onto thiol-covered gold: Platinum on a 4-mercaptopyridine SAM, Surf. Sci. 590 (2005) 146-153.

[16] M. Manolova, H.-G. Boyen, J. Kucera, A. Groß, A. Romanyuk, P. Oelhafen, V. Ivanova, D.M. Kolb, Chemical Interactions at Metal/Molecule Interfaces in Molecular Junctions-A Pathway Towards Molecular Recognition, Adv. Mater. 21 (2009) 320-324.

[17] F. Eberle, M. Saitner, H.-G. Boyen, J. Kucera, A. Gross, A. Romanyuk, P. Oelhafen, M. D'Olieslaeger, M. Manolova, D.M. Kolb, A Molecular Double Decker: Extending the Limits of Current Metal-Molecule Hybrid Structures, Angew. Chem. Int. Ed. 49 (2010) 341-345.

[18] M. Manolova, M. Kayser, D.M. Kolb, H.G. Boyen, P. Ziemann, D. Mayer, A. Wirth, Rhodium deposition onto a 4-mercaptopyridine SAM on Au(111), Electrochim. Acta. 52 (2007) 27402745.

[19] C.S. Kim, C. Korzeniewski, Cyanide adsorbed as a monolayer at the low-index surface planes of platinum metal electrodes: an in situ study by infrared spectroscopy, J. Phys. Chem. 97 (1993) 9784-9787.

[20] V.B. Paulissen, C. Korzeniewski, Infrared spectroscopy as a probe of the adsorption and electrooxidation of a cyanide monolayer at platinum under aqueous electrochemical conditions, J. Phys. Chem. 96 (1992) 4563-4567.

[21] C. Stuhlmann, Characterization of an electrode adlayer by in-situ infrared spectroscopy: cyanide on Pt(111), Surf. Sci. 335 (1995) 221-226.

[22] C. Stuhlmann, I. Villegas, M.J. Weaver, Scanning tunneling microscopy and infrared spectroscopy as combined in situ probes of electrochemical adlayer structure. Cyanide on Pt(111), Chem. Phys. Lett. 219 (1994) 319-324.

[23] J.L. Stickney, S.D. Rosasco, G.N. Salaita, A.T. Hubbard, Ordered ionic layers formed on platinum(111) from aqueous solutions, Langmuir. 1 (1985) 66-71.

[24] Y.-G. Kim, S.-L. Yau, K. Itaya, Direct Observation of Complexation of Alkali Cations on CyanideModified Pt(111) by Scanning Tunneling Microscopy, J. Am. Chem. Soc. 118 (1996) 393-400.

[25] M. Escudero, J.F. Marco, A. Cuesta, Surface Decoration at the Atomic Scale Using a Molecular Pattern: Copper Adsorption on Cyanide-Modified Pt(111) Electrodes, J. Phys. Chem. C. 113 (2009) 12340-12344.

[26] M. Escudero-Escribano, M.E. Zoloff Michoff, E.P.M. Leiva, N.M. Marković, C. Gutiérrez, Á. Cuesta, Quantitative Study of Non-Covalent Interactions at the Electrode-Electrolyte 
Interface Using Cyanide-Modified Pt(111) Electrodes, ChemPhysChem. 12 (2011) 2230-2234.

[27] M. Escudero-Escribano, G.J. Soldano, P. Quaino, M.E. Zoloff Michoff, E.P.M. Leiva, W. Schmickler, Á. Cuesta, Cyanide-modified Pt(111): Structure, stability and hydrogen adsorption, Electrochim. Acta. 82 (2012) 524-533.

[28] M. Escudero-Escribano, C. Wildi, J.A. Mwanda, A. Cuesta, Metallization of cyanide-modified Pt(111) electrodes with copper, J. Solid State Electrochem. 20 (2016) 1087-1094.

[29] J. Clavilier, R. Faure, G. Guinet, R. Durand, Preparation of monocrystalline Pt microelectrodes and electrochemical study of the plane surfaces cut in the direction of the $\{111\}$ and $\{110\}$ planes, J. Electroanal. Chem. Interfacial Electrochem. 107 (1979) 205-209.

[30] C. Wildi, G. Cabello, M.E. Zoloff Michoff, P. Vélez, E.P.M. Leiva, J.J. Calvente, R. Andreu, A. Cuesta, Super-Nernstian Shifts of Interfacial Proton-Coupled Electron Transfers: Origin and Effect of Noncovalent Interactions, J. Phys. Chem. C. 120 (2016) 15586-15592.

[31] G.A. Attard, R. Price, A. Al-Akl, Palladium adsorption on Pt(111): a combined electrochemical and ultra-high vacuum study, Electrochim. Acta. 39 (1994) 1525-1530.

[32] R. Hoyer, L.A. Kibler, D.M. Kolb, The initial stages of palladium deposition onto Pt(111), Electrochim. Acta. 49 (2003) 63-72.

[33] L.-J. Wan, T. Suzuki, K. Sashikata, J. Okada, J. Inukai, K. Itaya, In situ scanning tunneling microscopy of adsorbed sulfate on well-defined $\mathrm{Pd}(111)$ in sulfuric acid solution, J. Electroanal. Chem. 484 (2000) 189-193.

[34] B. Alvarez, V. Climent, A. Rodes, J.M. Feliu, Potential of zero total charge of palladium modified Pt(111) electrodes in perchloric acid solutions, Phys. Chem. Chem. Phys. 3 (2001) 3269-3276.

[35] M.J. Llorca, J.M. Feliu, A. Aldaz, J. Clavilier, Electrochemical structure-sensitive behaviour of irreversibly adsorbed palladium on $\mathrm{Pt}(100), \mathrm{Pt}(111)$ and $\mathrm{Pt}(110)$ in an acidic medium, J. Electroanal. Chem. 351 (1993) 299-319. 